\title{
Augusta Emerita y el territorio de la Praefectura regionis Turgaliensis en época augustea
}

\author{
Julio Gómez SANTa Cruz \\ Universidad de Extremadura \\ gstacruz@unex.es
}

\section{RESUMEN}

Con la fundación de Augusta Emerita se procede a la asignación de un amplio territorio a la nueva capital lusitana en el que se inscriben, entre otras, la Praefectura regionis Turgalium cuya delimitación aproximada al sureste de la provincia de Cáceres marcaba los límites del norte del ager emeritensis. Se plantea este trabajo una aproximación al territorio de dicha Praefectura a partir del estudio de los testimonios onomásticos proporcionados por colonos de ascendencia itálica, veteranos de las legiones y menciones de la tribu Papiria entre otros indicios epigráficos.

Palabras clave: Augusta Emerita. Ager emeritensis. Praefectura regionis Turgalium. Lusitania. Epigrafía. Onomástica. Colonización itálica.

\section{Augusta Emerita and the Territory of the Praefectura regionis Turgalensis in the Time of Augustus}

\begin{abstract}
After Augusta Emerita foundation, the assignment of a wide territory to the new Lusitanian capital begins. Among others, the Praefectura regionis Turgalium is included in this territory, and its approximated delimitation is outlined in the present work, based on the onomastic testimonies of settlers with italic roots, veterans of the legions and other references to the Papiria tribe. This is how the territory of the new Praefectura, located in the southeast of the province of Cáceres, is shaped up. This territory is also characterized by the abundant Roman onomastic.
\end{abstract}

Key Words: Augusta Emerita. Ager emeritensis. Praefectura regionis Turgalium. Lusitania. Epigraphy. Onomastic. Italic colonization.

Sumario: 1. Introducción. 2. El ager emeritensis. 3. El territorio de la Prefectura regionis Turgalium. 4. Valoraciones finales. 


\section{Introducción}

Uno de los aspectos más atractivos surgido de las trascendentales reformas de Augusto en la Lusitania fue la organización de los nuevos ámbitos administrativos que formaban las ciudades y territorios de dicha provincia. En ese sentido, la ocupación y explotación territorial fue especialmente sensible en el entorno de Augusta Emerita, promocionada ahora a la capitalidad provincial y a la que se otorgó un amplísimo territorio que se extendía más allá de sus límites, sobre los territorios de otras civitates vecinas bajo la denominación agronómico-administrativa de "Prefectura".

En efecto, si en un primer momento, el reparto del territorio de la colonia emeritense tuvo un claro componente militar (protagonizado básicamente por veteranos de las legiones $V$ Aluadae y $X$ Gemina), a ese primigenio proceso colonizador, se sumó el paulatino asentamiento de gentes de todo el Imperio, atraídas por las oportunidades que presentaba la esplendorosa capital lusitana y, entre ellas, colonos que acabaron asentados en los amplios territorios de las ciudades más próximas como Metellinum, Turgalium e incluso otras más alejados como Norba Caesarina o Lacinimurga. En ese sentido, es indiscutible el papel de Emerita Augusta como foco de atracción de emigrantes venidos desde la península itálica, atraídos por las infinitas posibilidades económicas que ofrecía, especialmente agrícolas -la explotación de las feraces tierras que componen su amplísimo territorio-, y comerciales como centro neurálgico de la red viaria y punto de recepción y distribución de todo tipo de bienes.

Las fuentes escritas (Frontino, Higinio, Sículo Flaco, Agenio Úrbico) ${ }^{1}$ y los numerosos estudios dedicados al territorio de Augusta Emerita permiten en la actualidad conocer el procedimiento del reparto de dicho territorio en lotes entre los colonos dentro de un proceso de centuriación. ${ }^{2}$ Pero nos interesa ahora, como los gromáticos también refieren, aunque sea de forma superficial, la formación de praefecturae zonales destinadas a ampliar el territorio primigenio emeritense. De esta forma, el gromático Higinio cita distintos distritos adscritos al territorio emeritense y entre ellos la Turgaliensis regionis Praefectura ${ }^{3}$ prefecturas añade Sículo Flaco que comprendían el territorio que una colonia incorporaba a costa de una ciudad vecina cuando la tierra disponible para asentar a los veteranos resultaba insuficiente. ${ }^{4}$ En esa misma línea,

1 Thulin 1913. Un elenco completo de las fuentes gromáticas para el entorno de Augusta Emerita en ARIÑo - GURT 1999, 46 ss.

2 Son numerosos los estudios sobre los límites del ager emeritensis y de la proyección del sistema de centuriación en la colonia. Sus conclusiones parten de la documentación escrita, de la delimitación de las fronteras expresada en hitos terminales (como los de Valdecaballeros o Montemolín) y de la observación del paisaje agrario en busca de las huellas de la centuriación romana. Vid. entre otras publicaciones: WiegELL 1976; SÁEz Fernández 1982; Gorges 1982; Sillières 1982; Álvarez Martínez 1988; Canto 1989, 1993; Ariño - Gurt 1994, 2005; LóPez de Paz 1993; Ramírez SÁdAba 1994; Gorges - RodríGuez Martín 2005; Saquete Chamizo 2004; Cordero Ruiz 2010.

3 ...divus Augustus in Veturia Emeritae iugerum CCCC, quibus divisionibus decimani habent longitudinis actus XL, kardines actus XX, decimanus est in orientem. Quibusdam deinde coloniis perticae fines, hoc est primae adsignationis, aliis limitibus, aliis praefecturae continentur. In Emeritensium finibus aliquae sunt praefecturae, quarum decimani aeque in orientem diriguntur, kardines in meridianum: sed in praefecturis Mullicensis et Turgaliensis regionis decimani habent actus XX, kardines actus XL (Higinio, Th., 135-136).

4 Sículo Flaco, Th., 124-125. 
era habitual que esas Prefecturas conservaran el nombre propio de la ciudad a la que pertenecía en origen. Estaríamos pues ante la "Prefectura de la zona de Turgalium" en el área en torno a la actual localidad de Trujillo identificada con la antigua Turgalium romana ${ }^{5}$ y cuyo territorio, según dicen las fuentes gromáticas, se situaba en los confines del ager emeritensis con una peculiar orientación de sus parcelas en dirección norte-sur, al contrario que la seguida en la pertica o núcleo del territorio emeritense. ${ }^{6}$ Debemos entonces preguntarnos: ¿Qué territorio comprendía la Prefectura Turgaliense? ¿Qué territorio se desgajó en beneficio de la capital emeritense del ámbito espacial de la antigua Turgalium? ¿Quiénes fueron sus beneficiarios y desde cuándo?

$\mathrm{Si}$ a la falta de nuevas referencias en las fuentes, añadimos la falta de excavaciones arqueológicas y la escasez de prospecciones sistemáticas tanto en la propia localidad de Trujillo como en las comarcas de los alrededores, por no hablar de la aún más problemática reconstrucción de las posibles "centurias fósiles", encontramos que la investigación sobre la Prefectura Turgaliense, se ha limitado en general a señalar de forma vaga su hipotética ubicación en torno a la actual localidad de Trujillo y al que fuera su territorio en época romana. ${ }^{7}$

Ante ese panorama, vamos a presentar un método de trabajo -fundamentado primordialmente en la epigrafía funeraria- con la intención de complementar los estudios al uso sobre los límites del ager emeritense. Contamos para ello con un sólido punto de partida: la extraordinariamente cuantiosa epigrafía del sureste de la provincia de Cáceres; centenares de inscripciones en el granito local que ofrecen una valiosa información y que vienen siendo objeto de estudio por el Proyecto de Investigación de la UEX "Lusitania". ${ }^{8}$ Dentro de dicha epigrafía llama poderosamente la atención los testimonios que mencionan soldados veteranos que fueron beneficiarios de los repartos en la zona; pero aún es mucho más cuantioso el número de inscripciones que delatan una onomástica plenamente romana y, dentro del nomenclátor de sus nomina gentilicium, con todas las matizaciones posibles, aquellos que apuntan a un origen itálico. Ello no debe extrañarnos en cuanto que el nomenclátor de nomina gentilicium itálico documentado en la Lusitania ${ }^{9}$ aparece concentrado, en su mayoría, en la capital emeritense; sin duda, el principal polo de atracción de la provincia para dichos colonos de origen itálico a la vez que plataforma para su distribución por su territorio incluido el de las nuevas Prefecturas.

\footnotetext{
5 Wiegels 1976; LóPez de PAZ 1993.

6 Advierte el profesor Eustaquio Sánchez Salor que esa misma orientación norte-sur se mantendrá en los ámbitos territoriales de las diócesis de Plasencia y Cáceres-Coria, mientras que la de Badajoz presenta una orientación este-oeste.

7 El territorio de Turgalium se supone comprendía una vasta zona limitada al norte por el Tajo, al sur por la frontera provincial actual, al oeste por los ríos Tamuja y Gibranzos hasta la comarca de Las Villuercas que, siguiendo el arco de la Sierra de Las Corchuelas, harían frontera por el este con el territorio augustobriguense.

8 Resultan, en ese sentido, imprescindibles para la elaboración de este trabajo los corpora de Inscripciones Latinas de Cáceres publicados por Julio Esteban Ortega para Norba y Turgalium: EsteBAN ORTEGa 2007 (= CILCC I) y 2012 (= CILCC II).

9 Nos referimos a las recopilaciones de Schulze 1991; Solin - Solomies 1988; Abascal 1994; y en especial el listado de gentilicios romanos de la Lusitania de Milagros Navarro en NAVARRo 2000 y el atlas del colectivo GRUPO DE MÉrida 2003.
} 
Con esas premisas, nuestro planteamiento de trabajo es el siguiente: entendemos que el testimonio reiterado de los antiguos Italici o emigrantes llegados de la península Itálica y de sus descendientes asentados en la Prefectura Turgaliense, coincidiría con la temprana ocupación, desde época augustea, de la Prefectura a la vez que su distribución espacial, definirá en buena medida el ámbito territorial de la misma. Vamos a rastrear, pues, en la epigrafía documentada en la zona turgaliense y sus alrededores la constatación de este fenómeno plasmado en la onomástica residual, esos nombres muy raros fuera de Italia que no suelen presentar más de una o dos menciones epigráficas en el ámbito peninsular; en suma, "fósiles onomásticos" en expresión de Milagros Navarro ${ }^{10} \mathrm{o}$, en esta ocasión, onomástica de la emigración. Por otro lado, si entendemos "denominarse" como una forma de definirse social, jurídica y geográficamente, ${ }^{11}$ podemos asimismo adentrarnos en el conocimiento no solo de las zonas específicas de ocupación en la regio Turgaliense, sino incluso en los procesos de inserción y cohabitación de aquellos colonos itálicos con las poblaciones indígenas desde la época augustea.

Sería factible por tanto que, tras una primera fase endogámica con uniones de emigrantes con lusitanos de tipo extrajurídico, siguieran, en el contexto de las transformaciones de época flavia, matrimonios entre miembros de esas familias itálicas ya asentadas con elementos de las nuevas oligarquías indígenas promocionadas por el derecho latino. ${ }^{12}$ Todo ello se traduce en la transmisión de estos nomina italica entre la población autóctona fruto de una continuidad desde aquellos primeros veterani legionarios ${ }^{13}$ premiados por Augusto junto a otros colonos ítalo-romanos llegados en esa época, hasta sus descendientes. Sin menoscabo todo ello de la llegada de nuevas oleadas posteriores de itálicos a lo largo del Alto Imperio.

Como un adecuado complemento a esos testimonios, se presta especial atención a las referencias, también muy numerosas, a la tribu Papiria; una de las tribus o distritos electorales a la que se adscribían los ciudadanos de Emerita Augusta en un contexto cronológicamente temprano. ${ }^{14}$ De igual manera, otros indicadores que nos dan idea del tipo de gentes asentadas desde un primer momento en la Prefectura, son la constatación de la devoción por parte de ciudadanos romanos a divinidades como Júpiter, pero sobre todo los ejemplos de devoción a deidades vinculadas con el mundo militar como Marte y la sugerente y reiterada advocación a la diosa Bellona.

Por último, la siempre delicada datación cronológica de los epígrafes seleccionados, por encima de las insalvables dificultades habituales, presenta cierta coherencia derivada tanto de la tosca elaboración, en el granito local, de las lápidas funerarias y aras votivas, como de la repetida estructura del formulario epigráfico donde predominan fórmulas funerarias abreviadas, ausencia de los dioses Manes, empleo de los tria nomina, filiación y tribu, cuando no la ausencia de cognomen. Todo un conjunto

10 NAVARro 2000, 281-297.

11 NAVARro 2000, 287.

12 Curchin 2000, 332; Pérez Vilatela 2000; Pando Anta 2005.

13 Edmonson - Hidalgo 2007, 479 ss.

14 Forni 1976; Redondo, 1987; D’EnCARnaÇAo 2004. 
de indicios que apuntan, grosso modo, a la época de Augusto y la primera mitad del siglo I d.C.

\section{El ager emeritensis}

Tras esta introducción del planteamiento metodológico, vamos a presentar un brevísimo estado de la cuestión centrado en los antecedentes de la Prefectura. La fundación de Augusta Emerita, como era preceptivo, implicó la adscripción al nuevo centro urbano de un territorio (ager) delimitado del resto del territorio provincial. De ese espacio rural una parte se distribuyó como propiedad privada (assignatio) entre los colonos que participaron en la fundación. Otra parte del ager se consideró propiedad pública de Emerita mientras que el resto quedaba como tierra no catastrada, sin asignar, jurídicamente subcesiva. En el primer caso, se estima que las centuriaciones de Emerita (puede que por su fundación ex novo) alcanzaron una extensión global de 60.000 ha (equivalentes a 1.200 centurias) en la zona sur de su territorio y de 30.000 ha en la zona norte. En esa amplísima parcelación se incluirían, como ya dijimos, no solo el territorium de la colonia, sino también partes incautadas del territorio de los enclaves vecinos, entre ellos, los de Turgalium. Las razones que llevaron a la administración emeritense a dotarse de esa Prefectura responderían a la demanda de tierras; si bien no hay que olvidar que algunos gromáticos, ${ }^{15}$ advierten que el territorio emeritense no llegó a agotarse dada la gran superficie de territorio del que disponía la colonia y ello a pesar de las tres asignaciones sucesivas iniciadas por los veteranos legionarios.

Pudiera coincidir entonces la constitución de la Prefectura Turgaliense con la reestructuración del territorio emeritense cuando, según interpreta parte de la investigación, tras limitar su territorio meridional frente a la Beturia en el río Anas, se le compensó concediéndole nuevos territorios al norte. ${ }^{16}$ En todo caso, dada la lejanía -70 km- entre la capital lusitana y Turgalium, hay que suponer que su colonización debió de producirse en un momento posterior al reparto y la centuriación del ager próximo al núcleo urbano emeritense, momento a partir del cual se iniciaría el establecimiento de algunos veteranos y fundamentalmente colonos de procedencia itálica, que llegados de la Bética, acabaron radicados definitivamente entre la población vetona. En ese sentido, la nueva prefectura trujillana permitiría un mejor control fiscal de una zona que, no lo perdamos de vista, había sido incorporada a la órbita romana tras sucesivos avatares que se remontan a las guerras lusitanas, a la revuelta sertoriana y, sobre todo, a las aún recientes campañas de César. ${ }^{17}$

15 Frontino, Th. 9; Ageno Úrbico, Th. 44.

16 Para esta propuesta y el debate suscitado por otras teorías sobre los límites del ager emeritensis: CoRDERO RuIz 2010, 151 ss.

17 Además de la obvia necesidad de tierra para los colonos aquella nueva prefectura surgida a raíz de las reformas de Augusto, estaba justificada -según algunos autores- por razones de índole militar, como un factor represor contra las poblaciones indígenas cercanas (ARIÑo - GURT 1994, 46 ss) o, apoyándose en la cita de Dión Casio (Hist. Rom. 53.25.2) pensar en una doble ocupación por colonos romanos e indígenas (CANTO 1989, 161). 
Posiblemente en relación con la puesta en marcha del proceso de colonización de la prefectura y el consiguiente desarrollo de nuevas formas de propiedad de la tierra y de la explotación agrícola se deba interpretar un epitafio - procedente de Villamesíasde un liberto del emperador Nerón. ${ }^{18}$ Solo es una hipótesis, pero es tentador pensar en la existencia de un fundus o pequeño dominio imperial en la zona; propiedades en la Lusitania que, según informa Plutarco, serán poco después objeto de expropiación por Sulpicio Galba ${ }^{19}$ En cualquier caso, parece innegable que la creación de la Prefectura aceleraba el proceso de romanización del flanco oriental lusitano en torno a la estratégica posición del antiguo oppidum trujillano latinizado como Turgalium en su papel de civitas y mansio de la vía que desde Augusta Emerita llevaba a Toletum siguiendo la ruta natural que comunicaba las tierras extremeñas con las mesetas carpetanas. ${ }^{20}$ Una ruta jalonada en esta zona, según los itinerarios, por las mansiones de Turcalium, Lacipea, Rodacis y Leuciana que, sin entrar ahora en su polémica identificación, coincidirían con algunas de las localidades de la zona turgaliense con mayores índices de romanización.

\section{El territorio de la Praefectura regionis Turgalium}

Una de las áreas, si no la principal, que acogió el territorio de la Prefectura corresponde, como vamos a comprobar a continuación, a los grandes llanos proyectados hacia el sur por las sierras centrales cacereñas hasta confundirse con las feraces Vegas Altas del Guadiana - en la transición oriental entre las actuales provincias de Cáceres y Badajoz-. Se trata de un amplio espacio integrado por los territorios sustraídos desde Emérita a los territoria de Metellinum y de Turgalium; una amplia y fértil zona adecuada para su parcelación y reparto entre los colonos atraídos por las oportunidades que ofrecían aquellas tierras administrativamente dependientes de la capital emeritense.

Allí encontramos, en la actual localidad de Villamesías, testimonios de algunos de aquellos colonos llegados desde la península itálica y cuyo recuerdo se mantiene en la onomástica de Quintus Atinius, ${ }^{21}$ de Marcus Blaesius Vegetus,,$^{22}$ o de Quintus Faracius Severus; ${ }^{23}$ gentilicios todos ellos, Atinius, Blaesius y Faracius, de raigambre ítalo-romano. ${ }^{24}$ En ese mismo contexto se encuadra el epitafio, desgraciadamente perdido, de un legionario veterano de legio $X X$ y adscrito a la tribu Papiria: Lucius

18 CIL II, 665.

19 Plutarco, Galba 5; Le Roux 1982, 93 ss.

20 Una revisión de ese trayecto viario en: GiL Montes 2002, 19.

21 CILCC II, 890. Cfr. el gentilicio Atinius (NAVARro 2000, 284) perteneciente al colono difunto y cuya esposa, Brita Floria, da sepultura con la arcaica expresión de pro pietate.

22 ILER 2682; CILCC II, 860.

23 AE 1991, 976; HEp 4, 1994, 205; CILCC II, 886. Faracius constituye un gentilicio muy raro, un fósil onomástico de origen itálico a partir de un antropónimo de posible raigambre etrusca, por lo demás solo atestiguado en el territorio emeritense (ESTEBAN 2012, 311 y nota 345 ).

24 Navarro 2000, 284. 
Hermelius. ${ }^{25}$ Es decir, un individuo de origen itálico, enrolado en la Legio vigesima al que le sobrevino la muerte en el lote de tierra recibido tras su licenciamiento. Sería pues este Lucius Hermelius uno de los beneficiados por los repartos que fueron definiendo un nuevo paisaje agrario en el amplio territorio de Emerita, resultado de las reformas administrativas emprendidas por Augusto tras el final de las guerras cántabro-astures en las que destacó la legión citada. ${ }^{26}$ Proporciona además Villamesías ejemplos de onomástica de especial rareza en el panorama epigráfico peninsular como los gentilicios Roscius, ${ }^{27}$ solo atestiguados en el territorio emeritense, Norsius, ${ }^{28}$ Boelius $^{29}$ o Celerius ${ }^{30}$ entre otros. Sobresale también el número de devotos con onomástica plenamente romana de Iuppiter, como es el caso de Alfius ${ }^{31}$ así como de la diosa Bellona. ${ }^{32}$

A escasos kilómetros de Villamesías, en la misma vega, de la villa prospectada en la "Dehesa Boyal" de la localidad de Abertura proceden estelas funerarias de gentes de procedencia itálica y beneficiados con el reparto de tierras en la praefectura turgalensis. Son los casos de Titus Caepasius Maxumus, ${ }^{33}$ Gaius Gargenna ${ }^{34}$ y Gaius Gergenna ${ }^{35}$ a su vez emparentados con gentes del $\operatorname{lugar}^{36}$ que entendemos como un ejemplo de los procesos de romanización que sobre la antigua sociedad vetona desencadenó durante el Alto Imperio la colonia emeritense y la ocupación de su amplio territorio. ${ }^{37}$

Contribuye a reafirmar la pertenencia de esta zona al ámbito administrativo emeritense el recuerdo de un difunto -cuyo nombre se ha perdido-, pero que refiere su pertenencia a la tribu Papiria, ${ }^{38}$ el distrito por antonomasia al que se adscribían los ciudadanos de Augusta Emerita. También en esta zona falleció un veterano miembro de la caballería auxiliar, un eques de la III Cohors Lusitanorum. ${ }^{39}$ Junto a estos

25 CIL II, 662; ILER 5670; CILCC II, 845.

26 Dicha unidad legionaria desempeñó una decisiva participación, junto con la legio X Gemina en las campañas contra cántabros y astures que, entre el 26 y el 19 y bajo la dirección del legado de Augusto para la Hispania Ulterior Lusitana, Publio Carisio culminaron la anexión a la órbita romana del noroeste hispano.

27 CILCC II, 877.

28 CILCC II, 848. Norsius constituye un unicum, es posible además que estuviera adscrito a la tribu Papiria.

29 CILCC II, 850.

30 CILCC II, 887.

31 CILCC II 841, 842.

32 CILCC II, 843. Se trata de un ara que, dada su tosquedad y formulario, se adscribe a la época augustea

33 ILER 2441; HAE 770; CILCC II, 421. El gentilicio Caepasius es de origen itálico (NAVARRo 2000, 284) y en su estela, tanto la usencia de la invocación de los Dioses Manes como el formulario epigráfico empleado apuntan a una cronología temprana.

$34 A E$ 1992, 959; HEp 5, 1995, 154; CILCC II, 412. Bien pudiera tratarse de un emigrante llegado del centro de la península Itálica y que se asentó en alguna de las civitates de la zona (Norba, Turgalium o la propia Emerita) para acabar por recibir un lote de tierra (Vid. en extenso NAVARRo 2000, 286-287 y nota 16).

35 CILCC II, 413. Seguramente el mismo individuo si atendemos a la variante intervocálica de ea muy repetida en la onomástica de la zona. (SAlas - Rosco 1993, 141).

36 Sobre estos tres casos en particular: NAVARRo 2000, 286-287 y nota 16.

37 No faltan, sin salir de Abertura, otros ejemplos de ciudadanos romanos casados con mujeres indígenas, caso de Severa esposa difunta de Tiberius Fabianus (CILCC II, 429).

38 AE 1992, 963; HEp 5, 1995, 158; CILCC II, 408.

39 CILCC II, 428. 
ejemplos sobresale el alto porcentaje de ciudadanos romanos entre los que destacan los Iulii, reflejo de la vinculación con la gens Iulia y la decisiva tarea emprendida por César en la Vettonia y luego continuada por Augusto. ${ }^{40} \mathrm{Un}$ comentario aparte merece la estela de Publius Norbanus Flaccinus, magistrado de la vecina Colonia Norba Caesarina enterrado en el fundus que aquí poseía. ${ }^{41} \mathrm{Y}$ es que, probablemente, algunos ciudadanos de Norba se hicieran con propiedades de tipo subcesiva en la zona de contacto entre los territorios de la colonia y de Turgalium.

Un poco más al sur, en Campo Lugar, tres inscripciones coetáneas a las anteriores y procedentes de la necrópolis de la "Vega de Medellín" presentan gentilicios itálicos, fósiles onomásticos conservados en la Lusitania como entendemos los casos de Furius, ${ }^{42}$ Farax $^{43}$ y Loreius. ${ }^{44}$ Asimismo, procedentes de la necrópolis situada en la finca de "Casa de la Vega", destacan 15 epitafios referidos a ciudadanos romanos ${ }^{45}$ donde no faltan referencias a la tribu Papiria como el de Quintus Cornelius Monta$n o .{ }^{46}$ Un indicio más de la pertenencia de este lugar al territorio de la colonia emeritense repartido en centurias y lotes. Otro ciudadano romano, Marcus Vibius Rufus, igualmente adscrito a la tribu Papiria, se documenta en la inmediata localidad de Alcollarín; ${ }^{47}$ su gentilicio, además, puede entenderse como de origen itálico. De ese mismo origen parece ser también la familia de los Vibii que se atestigua en Madrigalejo. ${ }^{48}$ Precisamente en esta localidad, recientes hallazgos aún inéditos, abundan en epitafios de cronología augustea e incluso anterior, pertenecientes a ciudadanos romanos, algunos de ellos como Marcus Iunius ${ }^{49}$ y Marcus Victorius Galba ${ }^{50}$ adscritos a la tribu Papiria.

Muy interesante es el epígrafe funerario procedente de Escurial ${ }^{51}$ de uno de los muchos veteranos de la Legio X Gemina, que recibió un lote de tierras en el territorio de la prefectura emeritense en la zona de Turgalium. Se trata de Gracilis o Gaius Racilius quien debemos suponer, tras su participación en la guerra contra cántabros y astures a las órdenes de Publio Carisio y que, una vez pacificada la zona, al igual

40 CILCC II, núms. 399 a 439 para el área de Turgalium. Para Mérida: Ramírez SÁDABA 1995.

41 CILCC II 425. Es posible que algunos ciudadanos de Norba se hicieran con propiedades en la zona de contacto entre los territorios de la colonia y de Turgalium, probablemente parcelas que no estaban adscritas de una forma clara al territorio colonial (ESTEBAN 2012, 34).

42 ILER 6217; AE 1967, 210; CILCC II, 466.

43 HEp 6, 1996, 224; CILCC II, 465. Un gentilicio cuyo lugar de procedencia se remonta al norte de Italia (NAVARro 2000, 284) y que por sus similitudes etimológicas se puede relacionar con el Faracius que antes citábamos en la vecina Villamesías.

44 HAE 735; CILCC II, 462.

45 Entre otros, los epitafios de Man (ius?) Metilus Asiaticus Ursilif. (CILCC II, 460), Quintus Valerius Pollio (CILCC II, 468), Secunda Helvia (CILCC II, 475), Sextus Clodius Urbanus (CILCC II, 477), Vitalis (CILCC II, 469); libertos imperiales: Catullus Augustini y Pollio Augustinus (CILCC II, 473 y 479 ); aras votivas tanto a Marte por parte de Marcus Fulvius Fabianus (CILCC II, 459) como a Júpiter-Iovi Optumo-por Marcus Armo[---] Curius (CILCC II, 458).

46 CILCC II, 467.

47 AE 1993, 956; HEp 5, 1995, 172; CILCC II, 446.

48 ILER 3620; EE VIII, p. 377, n 69 ; CILCC II, 617.

49 HEp 8, 1992, 88; CILCC II, 624.

50 CIL II, 5294; ILER 6319; CILCC II, 615.

51 AE, 1993, 978; HEp 5, 1995, 208; CILCC II, 502. 
que otros muchos eméritos, acabó por establecerse en el ager de la capital lusitana beneficiado por los repartos que premiaban su servicio de armas.

Más al este, las tierras de la actual Herguijuela debieron de constituir otro de los focos de atracción en los repartos de la prefectura turgaliense. En efecto, procedentes de la finca Valzarzoso, a cinco kilómetros de dicha localidad, destaca un ara, muy tosca, de granito rojizo, ofrecida a Iuppiter Optimus Maximus por Quintus Tussanius Iulianus un gentilicio este, Tussanius, propio de la onomástica itálica. ${ }^{52}$ Asimismo, de cronología muy temprana y morfología singular es la inscripción votiva dedicada a Bellona por miembros de la familia de los Verrucios. ${ }^{53}$ Nos encontramos ante dos generaciones que portan el gentilicio itálico Verrucius y que en el caso del hijo se muestra, además, devoto de la diosa Bellona $;{ }^{54}$ un indicio de la presencia de esta deidad en esta zona desde, por lo menos, los tiempos de Augusto. Otro gentilicio itálico documentado en Herguijuela es el perteneciente a la gens de los Artorii presente en la estela de Quintus Artorius Vetto adscrito además a la tribu Papiria; ${ }^{55}$ igual ocurre con Quintus Servilius Celer; ${ }^{56}$ ejemplos en fin de ciudadanos romanos inscritos en la tribu Papiria o entidad administrativa en la que eran estatutariamente incluidos los ciudadanos emeritenses y cuyo asentamiento en esta zona cercana a Turgalium se puede llevar a una época temprana.

Otro punto neurálgico de la Prefectura se sitúa en torno al paso natural definido por la Sierra de Santa Cruz, enclave estratégico de continua ocupación desde tiempos protohistóricos. Precisamente de la localidad de Puerto de Santa Cruz proceden tres ciudadanos inscritos en la tribu Papiria: Lucius Arruntius, ${ }^{57}$ Lucius Vocconius $^{58}$ y Casianus $^{59}$ este último de clara raigambre itálica. ${ }^{60}$ Es oportuno destacar que todos ellos proceden del yacimiento de "Los Villarejos" que se viene identificando con la mansio Leuciana; ${ }^{61}$ asimismo entre otros muchos ejemplos, del mismo yacimiento procede un Salvius cuyo gentilicio le pone en relación con antiguos beneficiarios de los repartos en la zona de Otón, ${ }^{62}$ a su vez puede que coetáneo del soldado Lucius Lepidius que resalta con su cognomen Hispanus su lugar de origen. ${ }^{63}$

Justo al lado, en Santa Cruz de la Sierra se encuentra el testimonio de otro veterano: Iulius Severi, un eques enrolado en las tropas auxiliares romanas que fue ente-

\footnotetext{
52 HEp 13, 2003/2004, 234; CILCC II, 513; NAVARro 2000, 284.

53 Parece que los Verrucii se extendieron preferentemente por el norte del conventus emeritense pues, además de este de Herguijuela, se localizan otros testimonios en Capera y en Norba (CIL II, 828; CILCC I, 173).

54 ILER 319; CILCC II, 518.

55 AE 1971, 154; CILCC II 523.

56 CILCC II, 523.

57 CILCC II, 655.

58 AE 1997, 417; CILCC II, 666.

59 CILCC II, 675.

60 NaVArro 2000, 284.

61 XXV It. Antonino 438.5. Seguirían a continuación y en dirección noreste las mansiones de La Cumbre identificada con Rodacis, en la Dehesa de Roa, donde se documentan no pocos restos romanos; Valdecaballeros y La Mata (San Gregorio) ya en Navalmoral de la Mata.

62 CILCC II, 667.

63 CILCC II, 654.
} 
rrado en la parcela aquí recibida. ${ }^{64}$ Coetánea parece una invocación a Iuppiter con el epíteto Maximus - una fórmula propia de inscripciones de la época de Augusto- cuya dedicante porta un gentilicio, Volsinii, inédito en la epigrafía peninsular que se ha querido poner en relación con la ciudad itálica de Volsina. ${ }^{65}$ Por lo demás, en ambas localidades, abundan epígrafes con onomástica romana y cronología temprana: son las familias de los Servilii, Pomponii, Helvii y de forma reiterada Iulii, el gentilicio más común en la zona de Turgalium y de especial importancia en el conventus emeritense. ${ }^{66}$

En esa misma zona serrana, la localidad de Ibahernando acumula una treintena de testimonios de la familia de los Norbani asentados en la demarcación más noroccidental de la Prefectura Turgaliense. ${ }^{67}$ Pero nos interesan ahora las evidencias de posibles colonos itálicos atestiguados en esta localidad como se deriva de los gentilicios Murrius ${ }^{68}$ y Roscius; ${ }^{69}$ ejemplo de "fósiles onomásticos" que son el resultado del antiguo desplazamiento de itálicos atraídos por las reparticiones de tierras llevadas a cabo en la capital de Lusitania a lo largo del Alto Imperio. También en ese contexto o como pervivencia de él podemos incluir la onomástica presente en Calvius, Catius y Perpetuus. $^{70}$

En ese mismo orden de cosas, y ya en la vertiente septentrional de la Sierra de Montánchez, en el territorio que se viene adscribiendo a la colonia norbense, se concentran distintos gentilicios itálicos: Albicius $^{71}$ y Pupelius $^{72}$ en Valdefuentes; Socconius, ${ }^{73}$ Naevidius ${ }^{74}$ y Turellius $^{75}$ en Ruanes; Cavius en Torre de Santa María ${ }^{76}$ y Papius en Salvatierra de Santiago. ${ }^{77}$ De igual manera, ya en Plasenzuela, cerca del oppidum vetón de Tamusia, en un contexto de explotación minera, se documenta otro

64 AE 1993, 965; HEp. 5, 1995, 248; CILCC II, 702.

65 CILCC II, 682; NAVARRO 2000, 284.

66 RAMÍREZ SÁDABA 1995.

67 En su mayoría con onomástica plenamente romana y con una cronología cercana al siglo I en los casos de Quintus Norbanus Q.f. Victor (CILCC II, 546), Gaius Norbanus Caturo y Quintus Norbanus Niger (CILCC II, 551); Sextus Norbanus Rufinus (CILCC II, 566); Lucius Norbanus Longinus (CILCC II, 570); Norbana Rufif. Rufina (CILCC II, 578); Norba C.f. Maurila (CILCC II, 579); Norbana Q.f. Secunda (CILCC II, 583).

68 CPIL 311; CILCC II, 550. Murrius es un gentilicio itálico puede que en relación con los Murri atestiguados en Conímbriga (NAVARRo 2000, 287).

69 ILER 3425; CILCC II, 56; NAVARRo 2000, 284.

70 CILCC II, 589, 590 y 553. Otros ciudadanos romanos asentados en la zona de Ibahernando cuya onomástica es poco frecuente en Hispania en estelas que apuntan a una cronología temprana son los casos de Tibrillius que costea el epitafio de Lucretia Q. f. Anus (CILCC II, 554); Gaius Iulius Montanus (CILCC II, 575); Quadratus Q. f. Iulia Materna (CILCC II, 548) y Licinia M. $f$. Secunda (CILCC II, 576). Algunos de esos ciudadanos se muestran devotos de Júpiter como es el caso de Publius Petronius Firmanus, un cognomen éste raro en Hispania (CILCC II, 533); o devotos de Mercurio (Coluau) como Publius Caecilius Maxsumus (CILCC II, 535).

71 CPILC 528; CILCC I, 370; Navarro 2000, 284.

72 CILCC II, 368. Puede que en relación con los Pupelii itálicos (Navarro 2000, 284).

73 AE 1993, 953; HEp 5, 1995, 240; CILCC I, 273; NAVARro 2000, 284.

74 CPILC 421; CILCC I, 275; NAVARRO 2000, 284.

75 CIL II, 685; ILER 916; CILCC I, 268; NAVARRO 2000, 284.

76 HEp 6, 1966, 249; CILCC I, 353; NAVARro 2000, 284.

77 CIL II, 1006; ILER 3913; CILCC I, 318; NAVARro 2000, 284. 
posible colono itálico ${ }^{78}$ Sobresalen por último en esta área, dada su onomástica de extrema rareza en Lusitania e Hispania, otros hipotéticos casos de emigrantes a su vez devotos de Júpiter Optimo Máximo y la enigmática diosa Bellona tan insistentemente documentada en la zona de Turgalium $^{79}$ y, a lo más seguro, reminiscencia de un pasado militar en cuanto divinidad vinculada a la guerra. ${ }^{80}$

Todo este conjunto documental aconseja llevar hasta la penillanura trujillano-cacereña, hasta la vertiente meridional del Almonte y sus afluentes, el territorio parcelado desde Augusta Emerita dentro de la Prefectura Turgaliense en detrimento, bien del propio territorio de Turgalium, bien del territorio de Norba Caesarina.

Como no podía ser de otra forma, terminamos este rápido recorrido por el espacio atribuido a la Praefectura regionis Turgaliensis, en la propia localidad de Trujillo cuya abundante epigrafía - en buena parte repartida entre la monumentalidad trujillana- proporciona nuevos ejemplos de gentilicios itálicos que ponemos en relación con los procesos de colonización de la zona. Son los casos de Orfius, ${ }^{81}$ Titius, $^{82}$ Valius $^{83}$ y puede que, dada la rareza onomástica, Cercius, Circinius y Cavius. ${ }^{84}$ Asimismo de Trujillo proceden nuevos testimonios de la tribu Papiria presentes en los epitafios de Caius Iulius Rufus ${ }^{85}$ y Quintus Sertorius Balbus; ${ }^{86}$ y también de veteranos legionarios, eméritos que terminaron aquí sus días como el eques Lucius Marcius Maxumus ${ }^{87}$ $\mathrm{o}$, muy fragmentada, la dedicatoria a un compañero de armas -contubernalis- de nombre perdido. ${ }^{88}$

Será en esa época cuando se inicie la paulatina promoción administrativa de Turgalium como reflejo de su nuevo papel en la Prefectura más septentrional emeritense. Puede que estemos ante un nuevo caso de "ciudad sin urbe" ${ }^{89}$ pues, a falta de mejores testimonios, es obligado destacar un ara votiva, desgraciadamente perdida, que hacía referencia a aediles y duoviri lo que confirmaría la promoción de Turgalium a la categoría de municipio; ${ }^{90}$ en esa misma línea, otra ara con la mención del Genio Turgalensium ${ }^{91} \mathrm{o}$, en fin, la placa de mármol ${ }^{92}$ que menciona un fanum o recinto sagrado pudiera ser que consagrado - cada vez son más los indicios-a la diosa Bellona

78 ILER 4144; CILCC II, 646.

79 Entre otros casos: la ofrenda de Quadratus a la diosa Bellona procedente de La Cumbre (CILCC II, 495) o el ara votiva a IOM por Caius Tussanius Clemes - puede que emparentado con el Tussanius de Herguijuelaen Madroñera (CILCC II, 629).

80 Salas 1982; GarCía Bellido 1996.

81 CIL II, 5284; CILCC II, 739; originario de las regiones de la Italia meridional (NAVARRO 2000, 286).

82 AE 1983, 500; CILCC II, 718; NAVARro 2000, 284.

83 AE 1977, 392; CILCC II, 818. Es muy singular este epígrafe de Publius Valius Placidus en cuya estela destaca la ornamentación de la cabecera (pico, escuadra y compás con plomada).

84 CILCC II, 764, 765 y 781; NAVARRO 2000, 284.

85 AE 1993, 934; HEp 5, 1995, 269; CILCC II, 760.

86 AE 1993, 925; HEp 5, 1995, 261; CILCC II, 751.

87 AE 1993, 929; HEp 5, 1995, 265; CILCC II, 756.

88 AE 1977, 399; CILCC II, 772.

89 Mangas ManjarRÉS e.p.

90 CIL II, 5276, CPILC 555, CILCC II, 728 con bibliografía.

91 CIL II, 618; CPILC 522; CILCC II, 726 con bibliografía.

92 CILCC II, 721. 
máxime si tenemos presente las abundantes advocaciones a dicha deidad por ciudadanos romanos. ${ }^{93}$

Al pie septentrional del roquedal trujillano se asentaron otros colonos como reflejan los gentilicios Villius en Aldea del Obispo ${ }^{94}$ o Publius Rutilius Munus en Santa Marta de Magasca. ${ }^{95}$ Estamos ante un nomen originario del Lacio muy extendido por el valle del Po y luego llegado a la Bética y, desde allí, a la Lusitania. ${ }^{96}$ Otra rama de esos mismos Rutilii se localiza en Torrequemada ya en el límite de la Prefectura Turgaliense y el territorium de la colonia Norba Caesarina.${ }^{97}$ Asimismo en Santa Marta sobresale Marcus Titius, otro caso de un individuo con onomástica itálica casado con Paula -hija de Aminus - o sea una mujer cuyo nomen es propio del ambiente indígena. ${ }^{98}$ Mientras que, en esa misma área geográfica, en Madroñera, se documenta un nuevo ciudadano romano que porta onomástica oriunda itálica -Tussanius $-{ }^{99}$ y en la Sierra de las Villuercas, se encadenan sucesivos ejemplos, en aras de cronología temprana, de tria nomina devotos del dios Marte en Cañamero, Garciaz y Logrosán. ${ }^{100}$

\section{Consideraciones finales}

¿Qué conclusiones podemos obtener de toda esta información? Si llevamos a un mapa el conjunto de hallazgos se observa cómo al suroeste de Turgalium se multiplican los testimonios epigráficos de una temprana ocupación y revalorización de este espacio surgido acorde a las necesidades de tierras requeridas por la singular colonia, capital conventual y provincial de Augusta Emerita. En ese sentido, cerca de cuarenta testimonios (incluidos los dudosos) con rasgos onomásticos que delatan un origen itálico, perfilan el epicentro del territorio de la regio Turgaliensis objeto de parcelación. Son los Atinios, Albicios, Blaesios, Cavios, Faracios, Loreios, Murrios, Papios, Pupellios, Titios, Tussanios, Verrucios, Vibios, Villios, etc. cuyas parcelas se situaban en los actuales términos municipales de Villamesías, Abertura, Campo Lugar, Madrigalejo, Ibahernando, Puerto de Santa Cruz, Santa Cruz de la Sierra, Plasenzuela, Ruanes, Trujillo y Herguijuela (Fig. 1).

En esa misma distribución se solapan los trece testimonios epigráficos referentes a la tribu Papiria de nuevo en las localidades de Villamesías, Abertura, Campo Lugar, Alcollarín, Madrigalejo, Puerto de Santa Cruz, Trujillo y Herguijuela. (Fig. 2) Coincide además ese espacio con los escasos, pero significativos cinco testimonios de

93 CILCC II, 722 y 723; García Bellido 1991, 147; GómeZ - Esteban 2010.

94 AE 1983, 498; CILCC II, 450; NAVARro 2000, 284.

95 ILER 3912; CILCC II, 707.

96 Vid. el interesante estudio de la familia de los Rutilii en el lusitano conventus pacensis en el territorio de Olisipo y Balsa esencialmente y sus relaciones con otras indígenas en J. D'EnCARNAÇAO 1984. Un rápido resumen y cuadro de los Rutilii en la Lusitania en NAVARro 2000, 287-290.

97 CILCC I, 515.

98 ILER 6212; CILCC II, 705; NAVARRO 2000, 284.

99 CILCC II, 629.

100 CILCC II, 482, 508 y 600. Esa expansión de Mérida hacia las estribaciones de la Sierra de GuadalupeVilluercas, sigue en el ámbito religioso-administrativo en época visigoda. 
veteranos legionarios y equites que descansan en estas tierras tras recibir sus prometidas y deseadas parcelas en Villamesías, Escurial, Santa Cruz de la Sierra y Trujillo (Fig. 3).

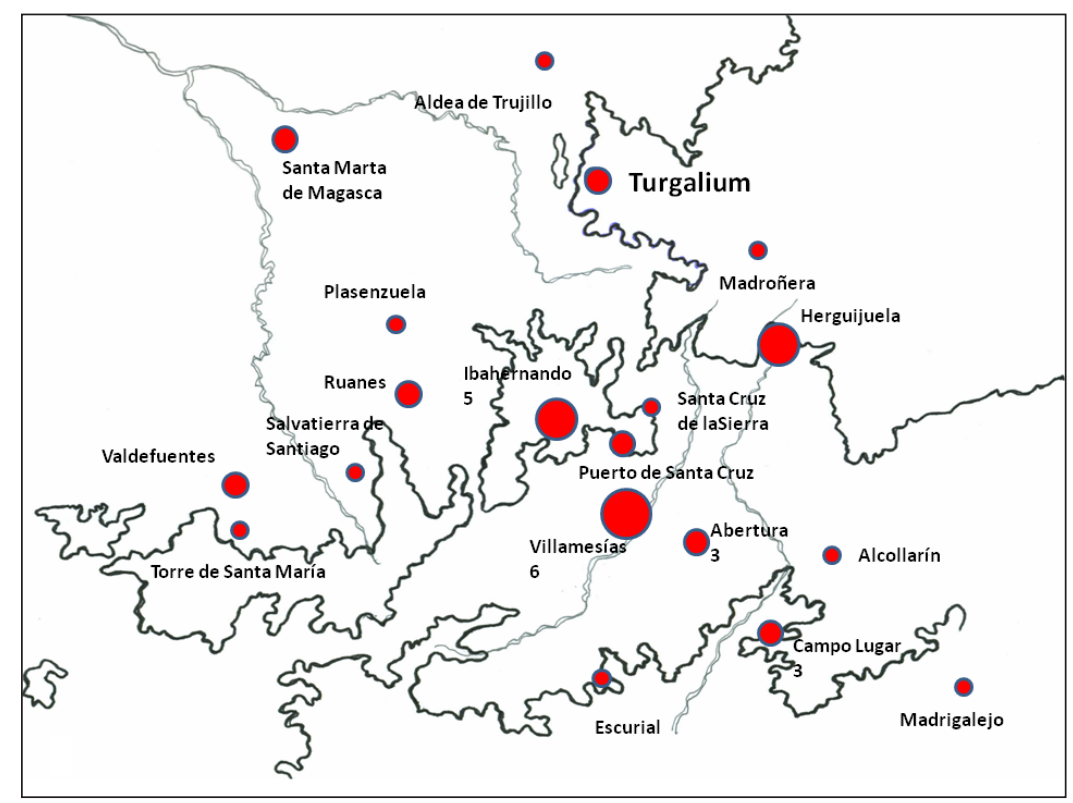

Fig. 1. Indicios onomásticos itálicos.

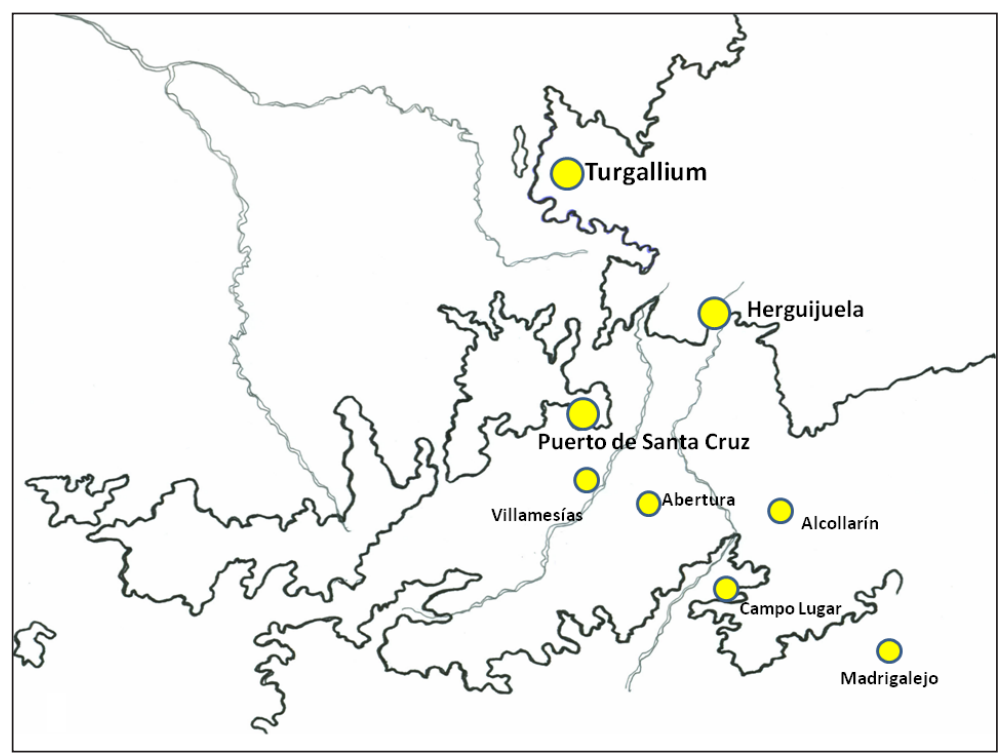

Fig. 2. Testimonios epigráficos de la tribu Papiria. 


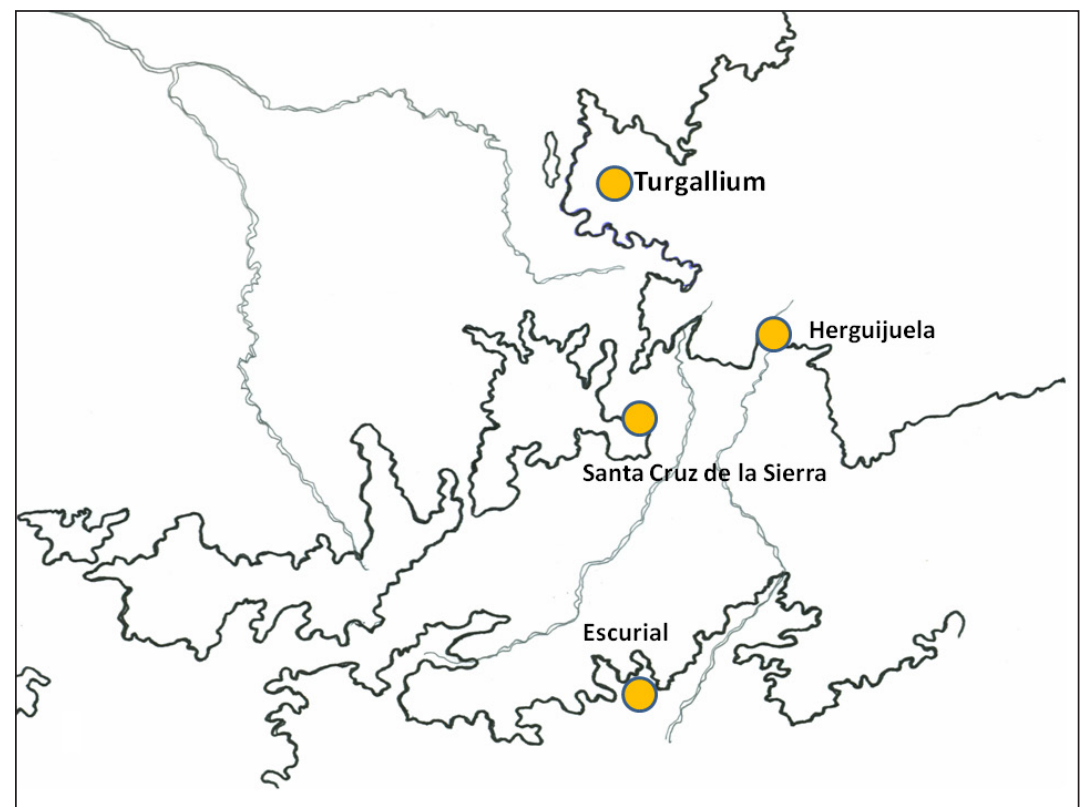

Fig. 3. Testimonios epigráficos de eméritos.

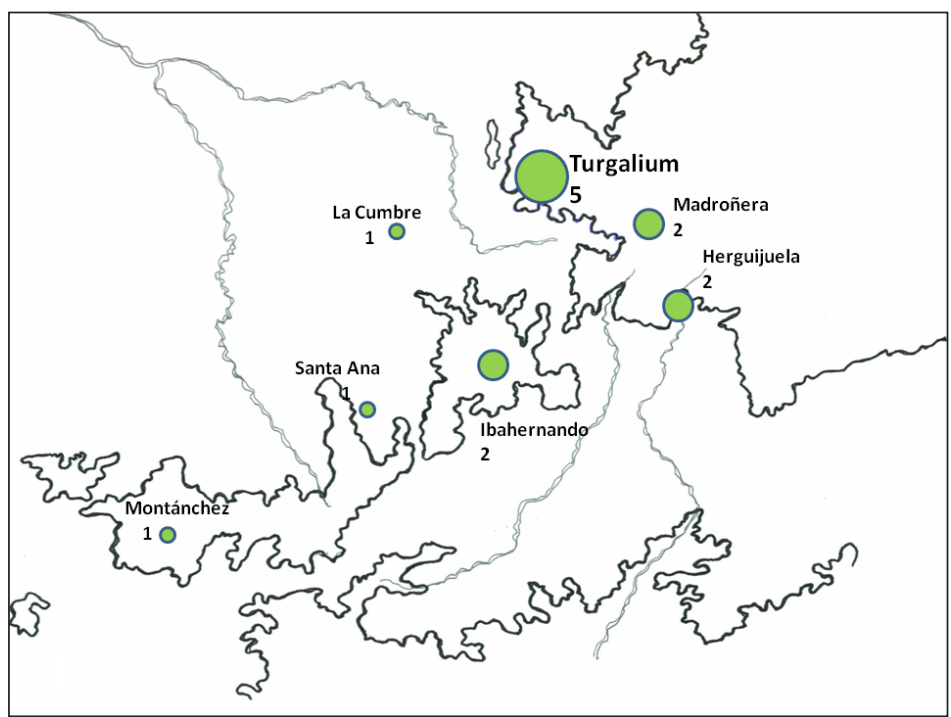

Fig. 4. Evidencias del culto a Bellona.

Desempeñaba también la Prefectura un papel religioso pues en ella se concentran las advocaciones, desde época de Augusto en adelante, a la diosa Bellona que, al modo de Ataecina en Alcuéscar, podemos suponer, tendría un santuario en la propia 
civitas de Turgalium. Catorce son las aras votivas ofrecidas por devotos con onomástica romana, todas ellas circunscritas al núcleo central de la Prefectura: Trujillo, Madroñera, Herguijuela, Ibahernando, La Cumbre, Santa Ana y Montánchez (Fig. 4). De igual manera, junto a las abundantes aras a Júpiter bajo distintas advocaciones, destacan las destinadas a Marte, el dios de la guerra romano, cuyos escasos testimonios de culto se concentran no solo al sur del Tajo, sino exclusivamente en el territorio turgaliense y más en concreto en las estribaciones montañosas de Las Villuercas.

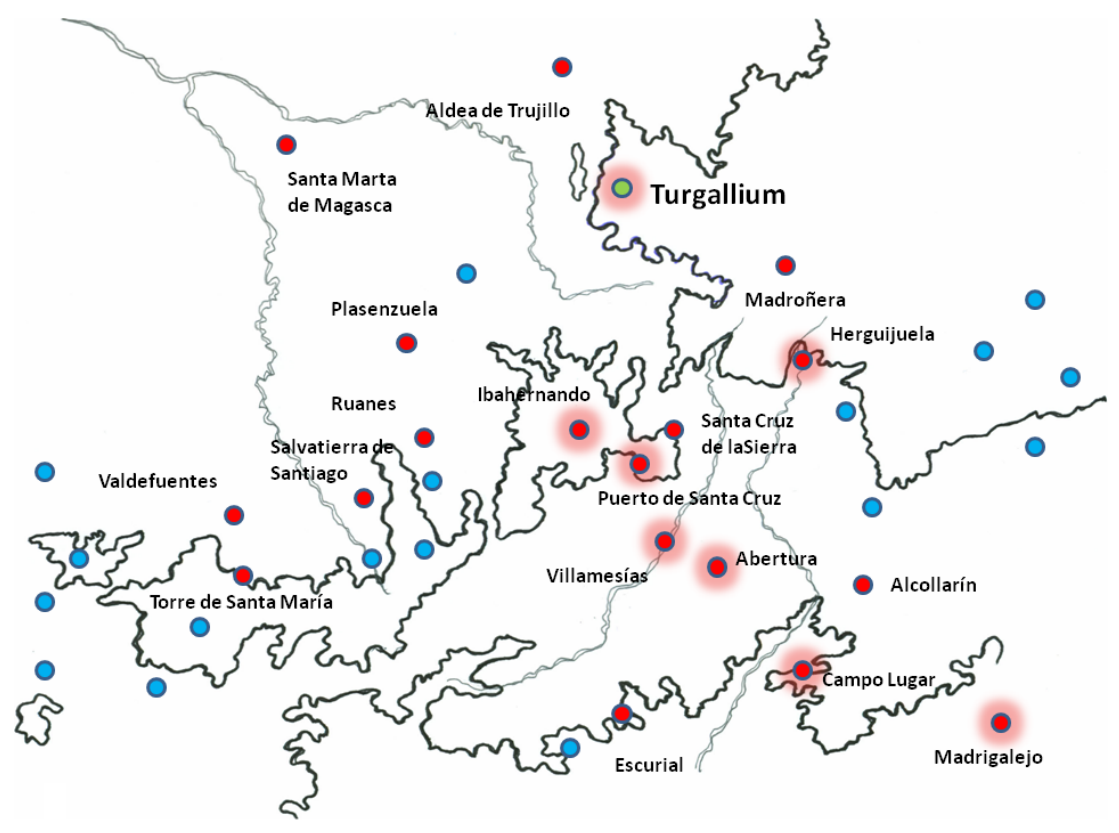

Fig. 5. Delimitación espacial de la Praefectura regionis Turgaliensis.

Corroboran, en fin, nuestra propuesta del ámbito territorial ocupado por la Praefectura Turgaliensis, dos abrumadoras constataciones. Por un lado, el excepcional alto porcentaje de onomástica plenamente romana en todas esas localidades citadas; fenómeno que se repite en las localidades vecinas, sin salir de esta zona, de este a oeste: Alia, Berzocana, Cañamero, Garciaz, Logrosán, Conquista de la Sierra, Zorita, La Cumbre, Santa Ana, Robledillo de Trujillo, Montánchez, Zarza de Montánchez, Miajadas, Arroyomolinos de Montánchez, Botija, Torremocha, Benquerencia, Aldea del Campo, Albalá, Casas de Don Antonio y Alcuéscar. Hay que destacar que, entre esa onomástica sobresale aquella vinculada a los Iulii, con treinta y cuatro ejemplos, resultado de las relaciones clientelares y la decisiva tarea emprendida por César y luego continuada por Augusto en la Lusitania oriental. Por otro lado, ratifica esta delimitación propuesta, la comprobación de una ostensible menor concentración de documentos epigráficos a la vez que el predominio de onomásticas eminentemente indígenas en las zonas colindantes con la Prefectura, ya en lo que serían los territorios 
de Norba y, más al norte, con unas características muy distintas de las que presenta la zona de Turgalium, los territorios de Capera y Caurium.

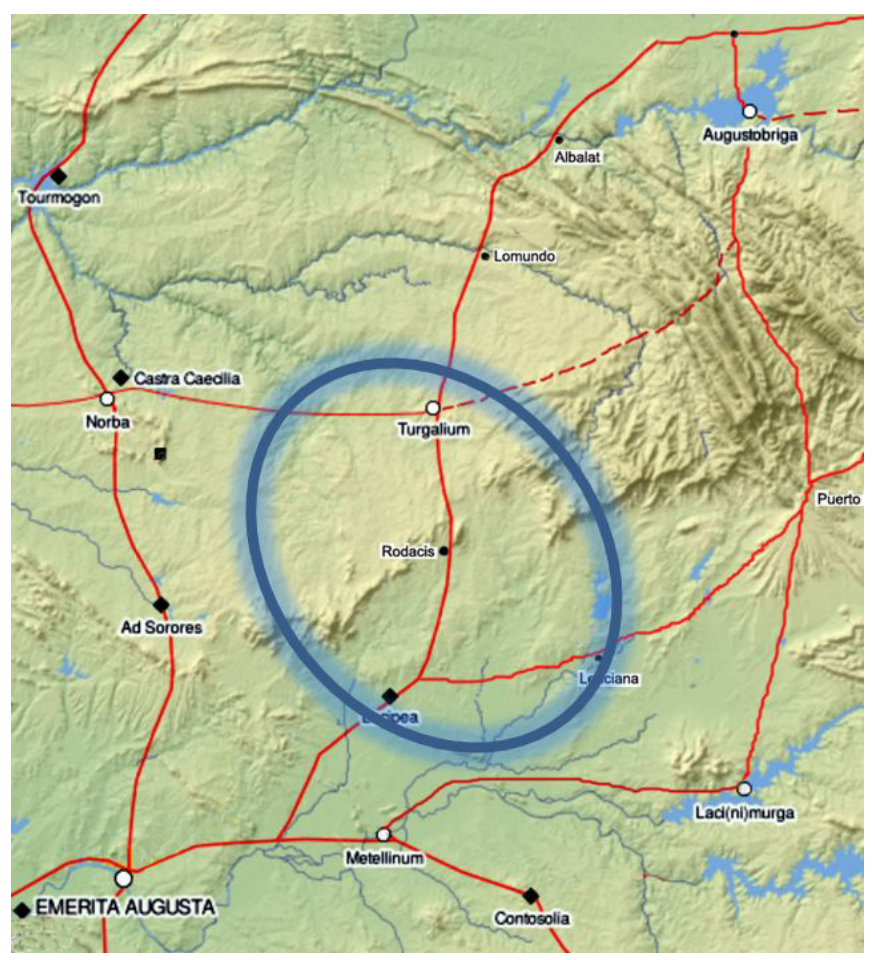

Fig. 6. Límites de la Praefectura regionis Turgaliensis.

Corresponde, en suma, el conjunto de estos testimonios epigráficos a buena parte del centro oriental de la provincia de Cáceres, en concreto al territorio donde confluyen las actuales comarcas del sureste de la penillanura del Salor, el suroeste de la comarca trujillana, toda la comarca de la Sierra de Montánchez y el norte de las Vegas Altas (Figs. 5 y 6). No parece además que esta Prefectura septentrional emeritense comprendiera todo el territorio de Turgalium, sino que la antigua entidad vetona sólo cedería parte del mismo al que se puede sumar una franja posiblemente deducida del territorio de Norba al norte y oeste, mientras que al sur y al este limitaría con los territorios de Augusta Emerita y Metellinum, éste último fronterizo con la vertiente norte del Guadiana hasta la zona de Miajadas. Constituiría por tanto la Prefectura Turgaliense, un territorio discontinuo, de grandes contrastes, tanto físicos como jurisdiccionales pero vertebrado por la ruta secundaria de la vía ab Emerita Caesaragustam como demuestran los enclaves, muy romanizados que jalonan su trayectoria de Abertura, Villamesías y Puerto de Santa Cruz. En conclusión, la formación de la Praefectura regionis Turgalium fue el resultado de las necesidades inherentes a la fundación de la propia capital Augusta Emerita y la paulatina parcelación de su 
amplio territorio acorde al asentamiento de veteranos de las legiones de Augusto y la llegada de colonos ítalo-romanos atraídos por las oportunidades que ofrecía la capital de Lusitania; un enclave que actuó como foco de atracción y a la vez de dispersión durante todo el Alto Imperio.

\section{Bibliografía}

Abascal Palazón, J. M. (1994): Los nombres personales en las inscripciones latinas de Hispania (=Anejos de Antigüedad y Cristianismo II), Murcia.

Álvarez Martínez, J. M.

(1981): "En torno a algunos aspectos de la fundación de Mérida", Revista de Estudios Extremeños 37, 155-161.

(1988): "Algunas observaciones sobre el territorium emeritense", [en] Homenaje a Samuel de los Santos, Albacete, 185-192.

AriÑo, E. - GuRT, J. M. (1994): "Catastros romanos en el entorno de Augusta Emerita. Fuentes literarias y documentación arqueológica”, [en] J. G. Georges - M. Salinas (eds.), Les Campagnes de la Lusitanie Romaine, Madrid-Salamanca, 45-67.

Ariño, E. - Gurt, J. M. - PALET, J. M. (2004): "Mérida y la estructuración del territorio lusitano", [en] El pasado presente. Arqueología de los paisajes en la Hispania Romana (=Acta Salmanticensia 122), 138-254.

Canto, A. M.

(1989): “Colonia Iulia Augusta Emerita: Consideraciones en torno a su fundación y territorio", Gerion 7, 149-205.

(1990) "Las tres fundaciones de Mérida", [en] W. Trillmich - P. Zanker (eds.), Stadtbild un Ideologie: die Monumentalizierung hispanische Städte zwischen Republik und Kaiserzeit, München, 289-297.

(1993): "Nuevas perspectivas en relación a la ordenación territorial del sur de la Lusitania española", [en] El medio rural en Lusitania romana. Formas de habitat y ocupación del suelo, Salamanca, 88-108.

Cerrillo, E. (2005): "El periodo romano y la época tardoantigua en la Tierra de Trujillo. Documentos arqueológicos para su estudio", [en] Actas del Congreso La Tierra de Trujillo, Cáceres, 25-57.

Cerrillo, E. et aliI (1994): “Ciudades, territorios y vías de comunicación en la Lusitania meridional española", [en] G. Georges - M. Salinas (eds.), Les Campagnes de la Lusitanie Romaine, Madrid-Salamanca, 51-72.

Clavel-Lévéque, M. (eds.) (1995): Cité et territoire. Colloque Européen, Beziers, Paris.

CORDERo RuIz, T. (2010): "Una nueva propuesta sobre los límites del ager emeritensis durante el Imperio Romano y la Antigüedad Tardía", Zephyrus 65, 149-165.

Curchin, L. A. (2000): "La famille lusitano-romaine", [en] J. G. Gorges - T. Nogales (coords.), Sociedad y cultura en Lusitania romana, Mérida, 249-268.

D’Encarnaçao, J.

(1984): Inscriçôes romanas do Conventus Pacensis, Coimbra.

(2004): "A mençao da tribu nas epígrafes-identificaçao e territorialidade", Anas 15-16, $127-132$. 
Edmonson, J. (2004): "Inmigración y sociedad local en Augusta Emerita, 25 A.C.-250 D.C.", [en] J. Gorges - E. Cerrillo - T. Nogales (eds.), Las comunicaciones (=V Mesa Redonda Internacional sobre Lusitania Romana), Madrid, 231-268.

Edmonson, J. - Hidalgo, L. A. (2007): "Hallazgos de dos epitafios de veterani en Mérida. Vidas paralelas de dos soldados Augustani (emeritenses) al final del siglo I d.C.", [en] Mérida. Excavaciones Arqueológicas. Memoria 10, 479-507.

Esteban OrTEGA, J.

(2000): "El proceso de romanización en Lusitania a través de la epigrafía", [en] J. G. Gorges - T. Nogales (coords.), Sociedad y cultura en Lusitania romana, Mérida, 249-268.

(2007) Corpus de Inscripciones Latinas de Cáceres, I Norba, Cáceres (= CILCC I).

(2012) Corpus de Inscripciones Latinas de Cáceres, II Turgalium, Cáceres (= CILCC II).

Fernández Corrales, J. M. - Cerrillo, E. (1980): “Contribución al estudio del asentamiento romano en Extremadura: Análisis espacial aplicado al S. Trujillo", Norba. Revista de Arte, Geografía e Historia 1, 157-176.

Forni, G. (1976): "La tribu Papiria di Augusta Emerita”, [en] A. Blanco Freijeiro (ed.), Actas Simposio Internacional Conmemorativo del Bimilenario de Mérida, Madrid, 33-42.

García Bellido, M. P. (1991): “Las religiones orientales en la Península Ibérica: documentos epigráficos I", AEA 64, 137-181.

Gil Montes, J. (2002): “El camino más corto entre Augusta Emerita y Toletus”, El Miliario Extravagante 81, 16-20.

Gómez Santa Cruz, J. - Esteban Ortega, J. (2010): "Divinidades y lugares de culto vetones y romanos en el noroeste de la provincia de Cáceres”, Norba. Revista de Historia 23, 49-64.

Gorges, J. G. (1982): “Centuriation et organisation du territorio: Notes preliminaires sur l'exemple de Merida", [en] P. A. Fevrier - P. Leveau (eds.), Villes et Campagnes dans l'Empire Romain, Aix-en-Provence, 101-110.

Gorges, J. G. - Rodríguez Martín, F. G. (2005): "Los territorios antiguos de Mérida. Un estudio del territorium emeritense y de sus áreas de influencia", [en] T. Nogales (ed.), Augusta Emerita. Territorios, espacios, imágenes y gentes en la Lusitania romana. (=Monografías emeritenses 8), Mérida, 93-128.

GruPo De MÉrida (2003): Atlas antroponímico de la Lusitania Romana, (M. Navarro - J. L. Ramírez coords.), Mérida.

Le RouX, P.

(1982): L'Armée romaine et l'organisation des provinces ibériques d'Auguste a l'invasion de 409, Paris.

(1999): "Le territoire de la colonie auguste de Mérida. Reéflexions pour un bilan", [en] J. G. Gorges - F. G. Rodríguez Martín (eds.), Économie et territoire en Lusitanie romaine, Madrid, 263-278.

LóPez DE PAz, P. (1993): “Consideraciones sobre el concepto y el estatuto jurídico de las praefacturae. El ejemplo de Emerita Augusta", [en] II Congreso Peninsular de Historia Antigua, Coimbra, 741-751.

MAngas Manjarrés. J. (e.p.): “Ciudades sin urbe en la Hispania romana”.

NAVARro, M. (2000): "Notas sobre algunos gentilicios romanos de Lusitania: una propuesta metodológica acerca de la emigración itálica", [en] J. G. Gorges - T. Nogales (coords.), Sociedad y cultura en Lusitania Romana, Mérida, 281-297. 
Pando Anta, M. T. (2005): La sociedad romana del conventus emeritensis a través de sus estelas funerarias, Mérida (=Cuadernos Emeritenses 31 ).

Palao Vicente, J. J. (2010): "El regreso de los veteranos legionarios hispanos a la península Ibérica", Hispania Antiqua 33-34, 85-110.

PéRez Vilatela, L. (2000): "De la Lusitania independiente a la creación de la provincia", [en] J. G. Gorges - T. Nogales (coords.), Sociedad y cultura en Lusitania romana, Mérida, $72-84$

RAMÍREZ SÁDABA, J. L.

(1993): "Dos termini augustales del territorium emeritense: uno de Valencia del Ventoso y otro de Montemolín", Veleia 10, 301-305.

(1994): "La demografía del territorium emeritense según la documentación epigráfica", [en] G. Georges - M. Salinas (eds.), Les Campagnes de la Lusitanie Romaine, MadridSalamanca, 131-151.

(1995): "Para-Representatividad demográfica en Emerita, vista a través de los Iulii", [en] F. Beltrán (ed.), Roma y el nacimiento de la cultura epigráfica en Occidente, Zaragoza, 271-279.

(2004):"Las comunicaciones en el territorium emeritense", [en] J. Gorges - E. Cerrillo -T. Nogales (eds.), Las comunicaciones (=V Mesa Redonda Internacional sobre Lusitania Romana), Madrid, 109-116.

Redondo, J. A. (1987): "La tribu Papiria: testimonios de la colonia Augusta Emerita en la Alta Extremadura", Boletín del MAN 3, 61-68.

RichardSON, J. S. (1996): "Conquest and colonies in Lusitania in the Late Republic and Early Empire", [en] E. Urbina - J. Santos (eds.), Teorías y práctica del ordenamiento municipal en Hispania (=Revisiones de Historia Antiqua 2) Vitoria, 53-61.

Ruiz del Árbol Moro, M. (2001): Organización y explotación del territorio en el noreste de Lusitania en época altoimperial, TD UCM, Madrid.

SÁEz FERnÁNDEZ, P. (1982): "Estudio sobre una inscripción catastral colindante con Lacimurga", Habis 21, 205-227.

Saquete Chamizo, J. C. (2004): "Territorios y gentes en el contexto histórico de la fundación de la colonia Augusta Emerita", [en] T. Nogales (ed.), Augusta Emerita. Territorios, Espacios, Imágenes y Gentes en Lusitania Romana, (=Monografías Emeritenses 5), Mérida, 373-397.

Salas, J. (1982): “Epígrafes a Mâ-Bellona”, Norba 3, 146-154.

SAlas, J. - Rosco, J. (1993): "Epigrafía latina de Abertura y Villamesías (Cáceres)”, Anas 4, 137-159.

Schulze, W. (1904) [1991]: Zur Geschichte lateinischer Eigennamen, Weidman, ZürichHildesheim.

Sillières, P. (1982): “Centuriation et voie romaine au sud de Mérida: contribution á la delimitation de la Bétique et de la Lusitanie", $M C V 18,437-488$.

Solin, H. - Solomies, O. (1988): Repertorium nominum gentilicium et congnominum Latinorum, Mainz.

Thulin, C. (1913): Gromatici veteres, Leipzig.

Wiegels, R. (1976): “Zum Territorium der Augusteischen Kolonie Emerita”, Madrider Mitteilungen $17,258-284$. 


\section{ANEXOS}

\section{ANEXO 1. TESTIMONIOS DE COLONOS ITÁLICOS EN LA PREFECTURA DE LA REGIO TURGALIENSIS}

\section{Abertura}

1) CILCC II, 421; ILER 2441; HAE 770.

T(itus) Caepasius / Maxumus / h(ic) s(itus) e(st)

2) CILCC II, 412; AE 1992, 959; HEp 5, 1995, 154.

Camira / Tertia f(ilia) / et liberta / an(norum) XXXV / h(ic) s(ita) e(st) / G(aius)

Gargenna /d(e) s(uo) f(aciendum) c(uravit)

3) CILCC II, 413.

[----] / [Am] / batif(ilia) an(norum) / XXXI / h(ic) s(ita) e(st) s(it) t(ibi) / t(erra) l(evis) Gergen / na vir et pa /ter f(aciendum) c(uravit)

\section{Alcollarín}

4) CILCC II, 446; AE 1993, 956; HEp 5, 19995, 172.

$M$ (arcus) Vibiu /s Rufus / Pap(iria) an(norum) L / h(ic) s(itus) e(st) s(it) / t(ibi) t(erra) l(evis)

\section{Aldea del Obispo}

5) CILCC II, 450; AE 1983, 498.

M(arcus) Villius M(arci) / L(ibertus) Philarguri / us h(ic) s(itus) e(st) / Hilarus / conlibertus / d(e) s(ua) p(ecunia) f(aciendum) c(uravit)

\section{Campo Lugar}

6) CILCC II, 466; ILER 6217; AE 1967, 210

Q(uintus) Furius / Niger h(ic) s(itus) / [e(st)] s(it) / t(ibi) t(erra) l(evis)

7) CILCC II, 465; HEp 6, 1996, 224

Q(uintus) Farax / [Q(uinti) f(ilius) Salvi[us] / an(norum) LXXV h(ic) s(it) / t(erra) l(evis) f(ilius) f(aciendum) c(uravit) / Q(uintus) F(arax) Modes / tus an(norum) $X X V / h$ (ic) s(itus) e(st) s(it) / t(ibi) t(erra) l(evis)

8) CILCC II, 462; HAE 735.

Loreia / M(arco) f(ilia) Laeta

\section{Herguijuela}

9) CILCC II, 513; HEp 13, 2003/2004, 234.

I(ovi) O(ptimo) M(aximo) / Q(uintus) Tussa(nius) / v(otum) s(olvit) / Iulianus / l(ibens)

10) CILCC II, 518; ILER 319.

Verrici / us Ve(rruci) f(ilius) B / elonae / l(inens) a(nimo) s(olvit)

11) CILCC II, 523; AE 1971, 154.

Q(uintus) Serv / ilius Q(uinti) f(ilius) / Pap(iria) Ce /lera n(norum) / XXX h(ic) s(itus) / est 


\section{Ibahernando}

12) CILCC II, 550; CPIL 311.

L(ucius) Mur / rius / Rufin / us an(norum) / Xh(ic) s(itus) e(st)

13) CILCC II, 56; ILER 3425.

Ros(cia) C(ai) f(ilia) / Ma [x]suma a[n(norum)]

14) CILCC II, 589.

G(aii) Calvi / an(norum) LV/h(ic) s(itus) e(st) s(it) t(ibi) t(erra) l(evis) / Sextia Calv[i?]

15) CILCC II, 590

Q(uintus) Catius / an(n)or(um) [----] / [h(ic)] s(itus) e(st) [----] /

16) CILCC II, 553

P(ublius) Petro / nius F/irminus / an(norum) XVh(ic) / s(itus) e(st) s(it) t(ibi) / t(erra) l(evis)

\section{Madrigalejo}

17) CILCC II, 617; ILER 3620; EE VIII, p. 377, nº 69.

C(aius) Vibius / Proculus / an(norm) L h(ic) s(itus) e(st) s(it) t(ibi) t(erra) / l(evis) Mus sania / M(arci) l(iberta) Mauril / la d(e) s(uo) f(aciendum) c(uravit)

\section{Plasenzuela}

18) CILCC II, 646; ILER 4144.

D(is) M(anibus) s(acrum) / L(ucius) Iulius Lasci / vi Ibarra an(norum) / XXXIII h(ic) s(itus) s)epulstus) e(st) / [s(it)] t(ibi) t(erra) l(evis) pater / f(ilio) f(aciendum) c(uravit) / [--- Las?]civi / [----]

\section{Puerto de Santa Cruz}

\section{9) CILCC II, 675}

Casia / [n] us Pap(iria) / [----]

20) CILCC II, 667

Amoena / Cae[ni]ci f(ilia) / an[n(orum)] LV / h(ic) s(ita) e(st) s(itI t(ibi) t(erra)

l(evis) / Salvius / verna f(aciendum) c(uravit)

\section{Ruanes}

21) CILCC I, 273; AE 1993, 953; HEp 5, 1995, 240.

L(ucius) Naevi / dus C(ai) / f(ilius) Nige / r an(norum) LXX / h(ic) s(itus) e(st) s(it) / t (ibi) t(erra) l(evis)

22) CILCC I, 275; CPILC 421.

Socini / a Secun / da L(uci) f(ilia) an(norum) / IX h(ic) s(ita) e(st) / s(it) t(ibi)

t(erra) l(evis) C(aius) Iu / lius p(ater) f(ecit)

23) CILCC I, 268; CIL II, 685; ILER 916.

Reve Ana / baeco / Afer Albibi / f(ilius) Turolus /v(otum) s(olvit) l(ibens) m(erito)

\section{Santa Cruz de la Sierra}

24) CILCC II, 682

Volsinia / L(uci) [f(ilius)] Cavia / votum / ovi M(aximo) / a(nimo) s(olvit) 


\section{Santa Marta de Magasca}

25) CILCC II, 707; ILER 3912. L(ucius) Rutili / us Mu / nus an(norum) / LVh(ic) s(itus) / e(st) s(it) t)ibi) t(erra) l(evis) / f(ili) f(aciendum) c(uravit)

26) CILCC, II, 705; ILER 6212.

Paula / Amini / h(ic) s(ita) est [s(it)] / tibi(t(erra) l(evis) M(arcus) T[i] / tiusus [---]

\section{Salvatierra de Santiago}

27) CILCC I, 318; CIL II, 1006; ILER 3913 L(ucius) Papius / Rufus f(ilius) / an(norum) XXX / hic t(ibi) s(it) t(erra) l(evis) / f(ilius) $f$ (aciendum) c(uraverunt)

\section{Torre de Santa María}

28) CILCC I, 353; HEp 6, 1966, 249.

L(ucius) Cav(ius?) S(exti) o Cav(iu)s / [B]alanus / Lac(ipeae) v(otum) s(olvit)

\section{Trujillo}

29) CILCC II, 739; CIL II, 5284 Q(uintus) Orfius / Asiaticus / ann(orum) VI et / XXX / LXXh(ic) s(itus) e(st) / s(it) t(ibi) t(erra) l(evis)

30) CILCC II, 818; AE 1977, 392. Pub(lius) Va / lius Pla /cidus [----]

31) CILCC II, 718; AE 1983, 500.

L(uciius) Titius C(ai) f(ilius) / Oivi Solutor(io) / porticum et ara[m] / v(otum) s(olvit) l(ibens) m(erito)

\section{Valdefuentes}

32) CILCC I, 370; CPILC 528. Peloris / C(ai) Albic(i) / Fusci[ni]/ser(va) an(norum) / III h(ic) s(ita) e(st) [s(it)] / [t(ibi) t(erra) l(evis)

33) CILCC II, 368. Paulla / Pupelli / a I(uli) l(iberta) an(norum) / C h(ic) s(ita) e(st) s(ibi ) t(ibi)

\section{Villamesías}

34) CILCC II, 890. $D$ (is) M(anibus) s(acrum) / Q(uintus) Atinius / C an(norum) LXXX / h(ic) s(itus) e(st) s(it) / t(ibi) t(erra) l(evis) / Britta Flor / ia pro pieta / te f(aciendum) c(uravit)

35) CILCC II, 860; ILER, 2682. M(arcus) Blaesi / us Vegetu(s) / h(ic) s(itus) e(st) s(it) / t(ibi) t(erra) l(evis)

36) CILCC II, 886; AE, 1991, 976; HEp 4, 1994, 205. D(is) M(anibus) s(acrum) / Q(uintus) Faracius / [Se]verus an(norum) / [----]h(ic) s(itus) e(st) s(it) / t(ibi) t(erra) l(evis)

37) CILCC II, 845; CIL II, 662; ILER 5670. L(ucius) Hermelius / L(uci) f(ilius) Pap(iria) Vet(eranus) leg(ionis) / XX / [----]

38) CILCC II, 877; ILER 5016. Alucius / Roscius C(ai) l(ibertus) / h(ic) s(itus) e(st) / Tureus / acoli(tus) C(ai) s(ervus)

39) CILCC II, 884; HEp 4, 1994, 208. 
D(iis) M(anibus) s(acrum) / [R]oscia / [----]

\section{ANEXO 2. TESTIMONIOS DE LA TRIBU PAPIRIA EN LA PREFECTURA DE LA REGIO TURGALIENSIS}

\section{Abertura}

1) CILCC II, 408; AE 1992, 963; HEp 5, 1995, 158.

C[----] / N[----]/ Pap(iria?) [an]nor / um L h(ic) s(itus) e(st) s(it) / t(ibi) t(erra) l(evis)

\section{Alcollarín}

2) CILCC II, 446; AE 1993, 956; HEp 5, 19995, 172.

$M$ (arcus) Vibiu / s Rufus / Pap(iria) an(norum) L / h(ic) s(itus) e(st) s(it) / t(ibi) t(erra) l(evis)

\section{Campo Lugar}

3) CILCC II, 467.

Q(uintus) Cor / nelius / Q(uinti) f(ilius) Pap(iria) / Montano / an(norum) LXI / h(ic) s(itus) e(st) s(it) / t(ibi) t(erra) / l(evis)

\section{Herguijuela}

4) CILCC II, 523; $A E$ 1971, 154.

Q(uintus) Serv / ilius Q(uinti) f(ilius) / Pap(iria) Ce /lera n(norum) / XXX

h(ic) s(itus) / est

CILCC II, 522; CPILC 760

Q(uintus) Artori / [us] Q(uinti) f(ilius) Pap /[i]iria Vett / [o] an(norum) V

$\mathrm{h}$ (ic) s(itus) / s(it) t(ibi) t(erra) l(evis) f(rater) / f(aciendum) c(uravit)

\section{Madrigalejo}

5) CILCC II, 624; HEp 8, 1992, 88.

M(arcus) Iuniu /s M(arci) f(ilius) Pap(iria) / h(ic) s(itus) e(st)

6) CILCC II, 615; CIL II, 5294; ILER 6319

M(arcus) Victori / us L(uci) f(ilius) Pap(iria) / Galba an(norum) / LXX h(ic) s(itus) e(st) / s(it) t(ibi) t(erra) l(evis)

\section{Puerto de Santa Cruz}

7) CILCC II, 675

Casia / [n]us Pap(iria) / [----]

8) CILCC II, 655

L(ucius) Arru / ntius L(uci) / F(ilius) Pap(iria) h(ic) / s(itus) est

9) CILCC II, 666; $A E$ 1997, 417.

Trujillo

L(ucius) Vocconius / L(ucii) f(ilius) Pap(iria) hic e(st) / sit [us] [-----]

10) CILCC II, 760; AE 1993, 934; HEp5, 1995, 269.

C(aius) Iulius [f(ilius)] / Pap(iria) Rufus / an(norum) C h(ic) s(itus) e(st)

s(it) [t(ibi)] / t(erra) l(evis) Rufill[a] / f(ilia) f(aciendum) c(uravit) 
11) CILCC II, 751; AE 1993, 925; HEp 5, 1995, 261.

Q(uintus) Serto / rius C(ai) f(ilius) / Pap(iria) Balb / u[s] [----] / P(ublio) [Se?]rvil / io [Al?]bi[no?] / [----]

\section{Villamesías}

12) CILCC II, 845; CIL II, 662; ILER 5670

L(ucius) Hermelius / L(uci) f(ilius) Pap(iria) Vet(eranus) leg(ionis) / XX / [----]

\section{ANEXO 3. TESTIMONIOS DE VETERANOS EN LA PREFECTURA DE LA REGIO TURGALIENSIS}

\section{Escurial}

1) CILCC II, 502; AE 1993, 978; HEp 5, 1995, 208.

[----] / Gracili[s] / veteranu / s leg(ionis) X G(eminae)

\section{Santa Cruz de la Sierra}

2) CILCC II, 702; AE 1993, 965; HEp 5, 1995, 248.

Iulius / Severi [f(ilius)] / équite

\section{Trujillo}

3) CILCC II, 756; $A E$ 1993, 929; HEp 5, 1995, 265

L(ucius) Mar(cius) / Maxu[mo] / equit[---]

4) CILCC II, 772; $A E$ 1977, 399.

[----] / Natalis / contubern(alis) / f(aciendum) c(uravit)

\section{Villamesías}

5) CILCC II, 845; CIL II, 662; ILER 5670.

L(ucius) Hermelius / L(uci) f(ilius) Pap(iria) Vet(eranus) leg(ionis) / XX / [----] 